\title{
Ciguatera fish poisoning
}

\author{
John A Crump, Colin L McLay, Stephen T Chambers
}

\begin{abstract}
Summary
Ciguatera fish poisoning is one of a variety of non-bacterial forms of human seafood poisoning. Consuming large predatory fish from tropical reef ecosystems may be hazardous. We describe a case that is typical of the disease, and illustrates the persistence of neurological symptoms that occur in some patients.
\end{abstract}

Keywords: ciguatera fish poisoning; ichthyosarcotoxaemia; poisoning; biotoxins

Department of

Infectious Diseases,

Christchurch Hospital,

Private Bag 4710,

Christchurch, New

Zealand

J A Crump

S T Chambers

\section{Department of}

Zoology, University of

Canterbury, Private

Bag 4800,

Christchurch, New

Zealand

C L McLay

Correspondence to Dr John A Crump, Fellow,

Department of Clinical

Microbiology, Duke

University Medical Center

Box 3879, Durham, NC

27710, USA

Accepted 13 May 1999
Humans who eat large predatory reef fish in the tropics risk the acute and sometimes severe neurological and gastrointestinal symptoms associated with ciguatera fish poisoning. Acute management is symptomatic and supportive. Intravenous mannitol may be of use. Sequelae include chronic dysesthesia, which may be relieved by amitriptyline.

Ciguatoxin is a lipid-soluble polyether compound $^{1}$ that is probably synthesised by specific bacteria after phagocytosis by the benthic dinoflagellate Gambierdiscus toxicus (figure 1). The organism adheres to dead coral surfaces and bottom-associated algae. The toxin is then concentrated in the food web as the dinoflagellates are eaten by herbivorous fish species that graze on algae and detritus. These fish are in turn eaten by the larger marine carnivores, which may then be eaten by humans. As the toxin concentration is elevated along the food chain, larger fish are likely to contain

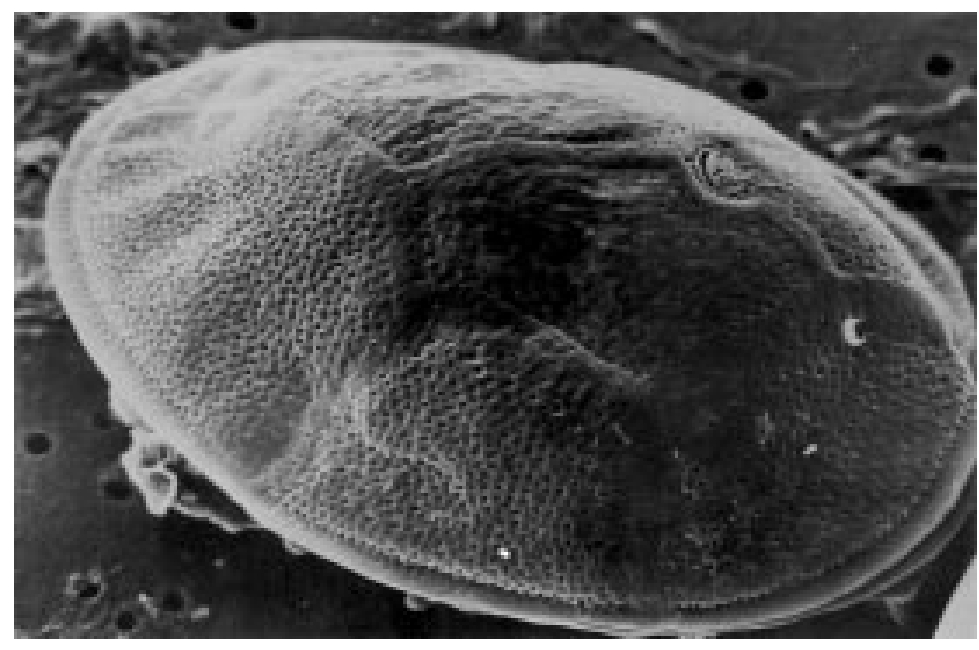

Figure 1 Electron micrograph of the benthic dinoflagellate Gambierdiscus toxicus. Actual diameter $60 \mu \mathrm{m}$. Reproduced with permission of CSIRO, Australia from Hallegraeff $^{11}$ larger concentrations of toxin. We present a case illustrating the acute and chronic manifestations of ciguatera fish poisoning in humans.

\section{Case report}

A 42-year-old man presented 3 weeks after returning from Fiji complaining of insomnia, lethargy, dysesthesia of hands and feet, occasional cramps in the calves, light-headedness on standing, and a dry mouth. While in Fiji he had eaten barbecued fish, and fed the remains to a local cat. Within three hours of eating the fish, he developed abdominal pain, watery diarrhoea, and developed a burning sensation of the skin overnight that became very severe the next day while swimming. He then developed increasing shortness of breath and noticed that the cat that ate the fish remains had died. The patient summoned the help of a local who viewed the fish remains, and noted them to be of a species commonly associated with fish poisoning, and suggested he go immediately to hospital. On arrival he was in marked respiratory distress, weak, and experiencing cramps. He required a period of respiratory supportive therapy. The following day he was maintaining adequate oxygenation without support, and was discharged. $\mathrm{He}$ returned to his home country. A diagnosis of ichthyosarcotoxaemia, clinically consistent with ciguatera fish poisoning, was made. Dysesthesia of the hands and feet persisted for weeks, but resolved after 5 days on amitriptyline $100 \mathrm{mg}$ daily.

\section{Discussion}

Ciguatera fish poisoning can occur in any region where humans eat carnivorous, and occasionally herbivorous, fish derived from tropical reef ecosystems. The toxin is unaffected by cooking, and no protective immunity is conferred by past exposure. In Fiji, Lutjanus spp, the Red Snapper or Red Bass (figure 2), and Plectropomus spp complex, the Coral Trout, are commonly implicated. The patient identified the Red Snapper as similar in colour and morphology to the fish he had eaten. Species which have been associated with ciguatera poisoning derive from the families Serranidae (groupers), Lutjanidae (snappers), Scaridae (parrot fish), Scombridae (mackerel), Muraenidae (moray eels), Sphyraenidae (barracudas), and Carangidae (jacks). Generally the disease occurs in a circumglobal belt between approximately $35^{\circ}$ north and $35^{\circ}$ south latitude, and is endemic in the tropical Indo- 


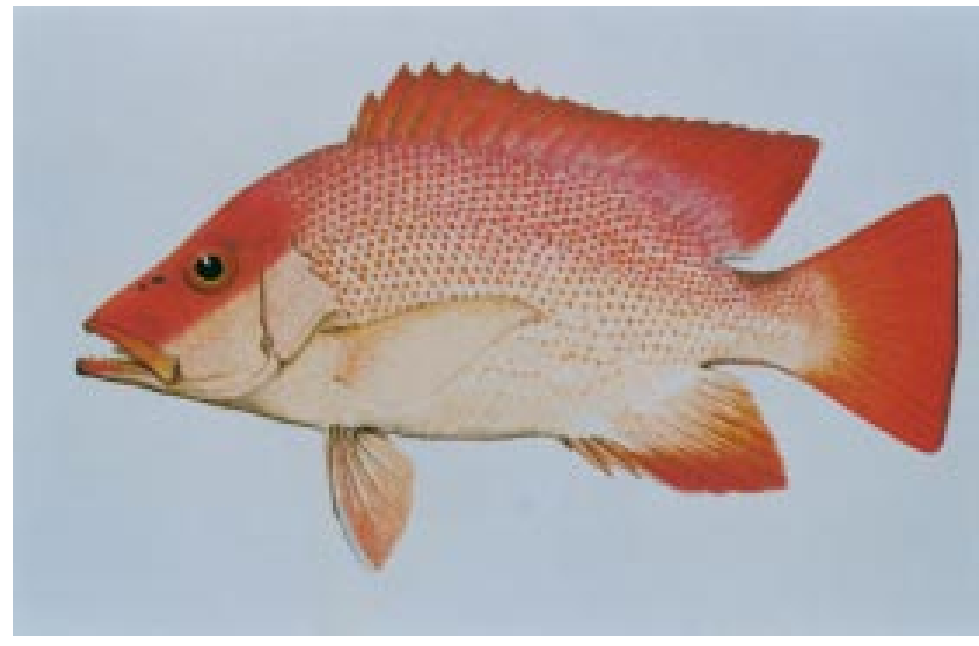

Figure 2 An example of Lutjanus spp, the Red Snapper or Red Bass. Reproduced with permission of HarperCollins Publishers, Australia, from Marshall ${ }^{12}$

Pacific Islands, and the Caribbean. Surveillance data suggests that incidence rates may be as high as 50 to 500 per 10000 population per year ${ }^{2}$ in the South Pacific region. The mortality rate is probably low with $0.1 \%$ being reported from a series from New Caledonia.

The mechanism of ciguatoxin-mediated disease in humans remains unclear. Suggested mechanisms include the 'opening' of sodium channels in cell membranes through the occupation of calcium sites, and both cholinergic and anticholinergic activity have been noted. ${ }^{4}$ The symptoms of ciguatera poisoning are well described, ${ }^{4}$ and include diarrhoea, vomiting, nausea, abdominal pain or cramping, bradycardia, hypotension, tachycardia, arthralgias, myalgias, paraesthesias of extremities, circumoral or facial paraesthesias, temperature reversal, asthenia, headache, pruritis, paresis, diaphoresis, dizziness or vertigo, ataxia, dyspnoea, and cough. As in our case, some symptoms may take weeks or months to resolve. ${ }^{5}$ The diagnosis is usually a clinical one, although it may now be supported by applying a rapid stick-enzyme immunoassay of horseradish and peroxidaselabelled sheep anti-ciguatera toxin antibody to the implicated fish.

Acute management is primarily supportive. Symptoms may be accentuated by the ingestion of alcohol. There is no available antitoxin. Anti-emetics, antidiarrhoeals, and intravenous rehydration are often necessary. Atropine has

1 Scheuer PJ, Takahashi W, Tsutsumi J, Yoshida T. Ciguatoxin: isolation and chemical nature. Science 1967;155:1267-8

2 Lewis ND. Disease and development: ciguatera fish poisoning. Soc Sci Med 1986;23:983-93.

3 Bagnis R, Kuberski T, Laugier S. Clinical observations on 3009 cases of ciguatera (fish poisoning) in the South Pacific. Am f Trop Med Hyg 1979;28:1067-73.

4 Barton ED, Tanner P, Turchen SG, Tunget CI, Manoguerra A, Clark RF. Ciguatera fish poisoning. A Southern California epidemic. West $\mathcal{F}$ Med 1995;163:31-5.

5 Pearn JH. Chronic fatigue syndrome: chronic ciguatera poisoning as a differential diagnosis. Med f Aust 1997;166:30910.

6 Auerbach PS. Ciguatera toxin poisoning. West f Med 1985; 142:380-1.

\section{Learning points}

- ciguatoxin is synthesised by bacteria phagocytosed by the benthic dinoflagellate Gambierdiscus toxicus

- ciguatoxin concentrates in the food web, reaching particularly high levels in large predatory reef fish

been used for treatment of symptomatic bradycardia. ${ }^{6}$ Intravenous calcium gluconate may have some theoretic benefit in counteracting the inhibition of calcium uptake by excitable membranes. ${ }^{7}$ Pralidoxime chloride has been used as a cholinesterase reactivator based on laboratory data that suggests that ciguatera toxin acts as a cholinesterase inhibitor, although a controlled trial has not been carried out. ${ }^{7}$ Amitriptyline has been shown to provide variable relief from the neurological symptoms associated with ciguatera poisoning, perhaps by membrane stabilisation via sodium channel blockade, or through its anticholinergic activity. ${ }^{8}$ An uncontrolled study using intravenous mannitol 0.5 to $1.0 \mathrm{~g} / \mathrm{kg}$ in a $20 \%$ solution given over 10 to 30 minutes produced immediate resolution of symptoms in most of 24 patients so treated. ${ }^{9}$ The mechanism of action is unclear, but may be related to membrane stabilisation.

Ciguatera fish poisoning is one of a variety of non-bacterial forms of seafood poisoning in humans. Others include paralytic, diarrhoetic, and amnesic shellfish poisoning, all of which are derived from dinoflagellate blooms, puffer fish poisoning due to tetrodotoxin, and clupeotoxism, ${ }^{10}$ which is also common in Fiji. Ciguatera fish poisoning may represent an under-reported and under-recognised cause of morbidity amongst travellers. Practitioners should consider including this health hazard amongst topics discussed with travellers prior to departure overseas. Tourists at greatest risk include those going on fishing tours, especially if they are not accompanied by an experienced local guide. Travellers should be warned of the risk and advised to avoid eating large predatory reef fish from tropical waters.

I would like to thank Mr Raymond Morse for kindly reviewing his own experience of ciguatera poisoning, and examining fish atlases to identify the likely offending species.

7 Morris JG Jr, Lewin P, Hargrett NT, Smith CW, Blake PA, Schneider R. Clinical features of ciguatera fish poisoning; a study of the disease in the US Virgin Islands. Arch Intern Med 1982;142:1090-2.

8 Bowman PB. Amitriptyline and ciguatera. Med F Aust 1984; $140: 802$

9 Palafox NA, Jain LG, Pinano AZ, Gulick TM, Williams RK, Schatz IJ. Successful treatment of ciguatera fish poisoning with intravenous mannitol. $7 A M A$ 1988;259:2740-2.

10 Narayan Y. Fish poisoning in Fiji. Fiji Med 1980;8:567-74.

11 Hallegraeff GM. Plankton: a microscopic world. Australia: CSIRO, 1988.

12 Marshall TC. Fishes of the Great Barrier Reef and coastal waters of Queensland. Sydney: Angus \& Robertson Ltd, 1964. 